\title{
LONG TERM EFFECTS OF FORMALDEHYDE PRESERVATION ON SUBSEQUENT BONE MACERATION PROCEDURES: A COMPARATIVE STUDY BETWEEN COLD AND HOT WATER MACERATION
}

\author{
Ayodeji S.O. ODUKOYA $*^{1}$, Oluwaseun AJANI ${ }^{2}$, and Taiye S. ADELODUN ${ }^{1}$ \\ ${ }^{1}$ Department of Anatomy and Cell Biology, Obafemi Awolowo University, Ile-Ife, Osun State, Nigeria. \\ ${ }^{2}$ Department of Anatomy, Bowen University, Iwo, Osun State, Nigeria \\ Correspondence to Ayodeji S.O. ODUKOYA, Department of Anatomy and Cell Biology, Obafemi Awolowo \\ University, Ile-Ife, Nigeria; Tel: +2348036153842, PMB: 013. E-mail: goshevnigeria@yahoo.com
}

\begin{abstract}
This study was conducted to compare the effectiveness of cold and hot water maceration techniques for the development of bone specimens from cadavers. Three already dissected bodies of both sexes (two males and a female) obtained from the Department of Anatomy, Bowen University, Iwo, Osun State, Nigeria were used. The male bodies were labelled as $A$ and $B$ and the female as $C$. Before maceration, the heights of the bodies were taken to be $165 \mathrm{~cm}, 170 \mathrm{~cm}$ and $160 \mathrm{~cm}$ for A, B and C respectively. The bodies were preserved in formalin for 4 years before being used. Hot water maceration involves cooking bones in water. Bodies $\mathrm{A}$ and $\mathrm{C}$ were used in this method. While cold water maceration is simply by soaking the body in water until all the remaining flesh was removed. Hot water maceration showed changes in color of the bones, shrinkage of the bones, oily substances were seen on the surface of the chloroform during degreasing and the bones were very soft after bleaching but got harder after drying with sunlight. Cold water maceration on the other hand kept the bones white and maintained their integrity though it required a lot of time. Small bones had their flesh removed quickly in few weeks, while larger and longer bones took months. We conclude that cold water maceration done properly, results in cleaner bones and better morphological outcomes than hot water method though it requires much time. KEYWORDS: Maceration, Formaldehyde, Comparative, Bones, Hot water, Cold water
\end{abstract}

\section{INTRODUCTION}

Preparation of the skeleton of a deceased being for long term curation includes tissue maceration and removal, bone disarticulation, bone cleaning, bone degreasing, bone bleaching and labeling or articulation (Greene et al., 1993). Depending upon the size of the body, each of the preceding processes may vary in the amount of time they require. For example, a toddler requires much less time in the maceration process before the bones could be disarticulated than that of an adult (Hussain et al., 2007). However, there are 3 main methods of bone maceration: Cold Water Maceration, Hot Water Maceration and Dermestes (Christenson, 2005). Cold Water Maceration is the simplest method of maceration which simply has to do with soaking the fleshed-out bones in cold water until all the remaining flesh has been removed. The time required to remove all the flesh varies with the size of the skeleton and the temperature of the water (Offele et al., 2007). Hot Water Maceration ("cooking") is simply a speeded-up process of maceration. Cooking bones in water must be done carefully and the bones checked often. Cooking should be done outdoors when possible. Boiling the bones can destroy disease causing organisms, but at the same time, it can damage the bones. However, larger and heavier bones can be gently boiled and smaller, more delicate bones should be gently simmered to prevent damage (Christenson, 2005). Dermestes which denotes several species of beetles in the genus

Submitted $26^{\text {th }}$ June 2017 , revised on $29^{\text {th }}$ June 2017. Published online $12^{\text {th }}$ July 2017 . To cite: Odukoya ASO, Ajani O, Adelodun TS. Long Term Effects Of Formaldehyde Preservation On Subsequent Bone Maceration Procedures: A Comparative Study Between Cold And Hot Water Maceration. Anatomy Journal of Africa. 2017. 6 (2): 1000 - 1008. 
"Dermestes" on the other hand, feed on dried flesh and can be very effective bone cleaners. Both the adult Dermestes beetles and the larvae feed on flesh, but the larvae consume a greater amount of flesh and are much more efficient bone cleaners (Offele et al., 2007).

Cold water maceration is regarded as the best method to get good outcomes in bone curation processes; but most often hot water maceration is usually employed in human bones maceration because of the length of time required to carry out effective maceration with cold water. The questions arise; when cadavers have been preserved in formaldehyde for several years, is it advisable to still employ hot water maceration and does the maceration procedure used affect the final outcome of the macerated bones? The current research work sets out to answer these questions through the comparison of the effectiveness and outcomes of cold and hot water bone maceration methods and ascertaining if long term storage in formaldehyde affects subsequent maceration of bones.

\section{Source of Cadavers}

Three already dissected bodies of both sexes (two males and a female) obtained from the Department Anatomy, Bowen University, Iwo, Osun State, Nigeria were used for this study. The male bodies were designated as bodies $\mathrm{A}$ and $\mathrm{B}$ and the female body as body $C$. Before the process of maceration started, the heights of the 3 bodies were taken to be $165 \mathrm{~cm}, 170 \mathrm{~cm}$ and $160 \mathrm{~cm}$ for $\mathrm{A}, \mathrm{B}$ and $\mathrm{C}$ respectively. The three bodies had been preserved in formalin for a duration of 4 years before they were used.

\section{Instruments used}

The list of the instruments used is as follows; Scalpel blade, Knives, Drum, Baskets, Firewood, Wires, Drilling machine (Itco Drilling Machines, India), Plastic buckets, Hand gloves, Stretcher, A piece of iron rod, Shovel, Digger, Small pieces of labeled bags, Plank; $20 \mathrm{~cm} \times 20 \mathrm{~cm}$, Broom, Binding wire, Iron rod, Plier, Plastic container, Tape rule, Cutter and Dunlop.

\section{Chemicals and Reagents used}

Chloroform --- (Dow Chemical Company, USA), Hydrogen peroxide --- (OCI Chemical

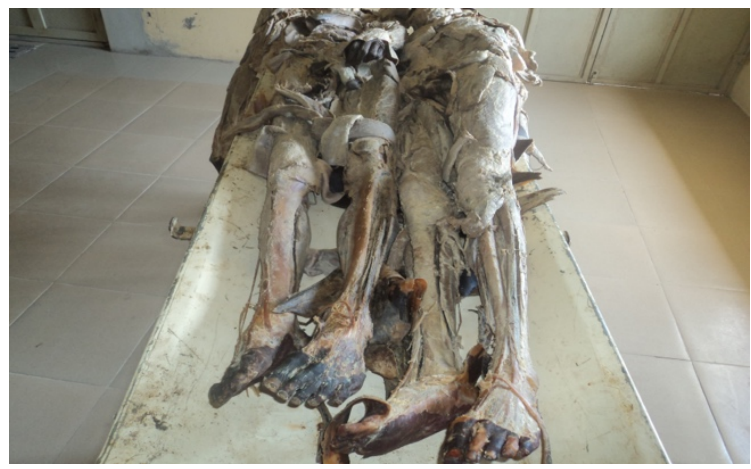

Figure 1: Showing the two Cadavers Male and Female Before De-fleshing i.e the whole dissected bodies with remains of muscles, skins and other connective tissues still intact as they were removed from the storage tank. 


\section{First Round of De-fleshing}

The bodies went through the first round of defleshing using a knife and a scalpel blade detaching a large percentage amount of the tissues from the bones as much as possible. This was done so as to hasten the process of boiling. As the flesh were removed, they were thrown inside a plastic basket.

During this first round of de-fleshing, care was taken to avoid the mixing up of the male and the female bones. After de-fleshing the two bodies, the removed flesh was buried so as to avoid unpleasant odor and infections in the environment.

\section{Boiling}

Before boiling, all the internal organs in the cadavers were removed. Because the bones of both bodies will be boiled together, a copper wire was used to bind the long bones of the male, separately from that of the female. The long bones of both bodies were bound very tightly and separately so as to avoid mix-up of bones during boiling. For the smaller bones like bones of the hands and foot, they were separated using small pieces of bags. For both bodies, the bones of the right hand were but in a biece of baa. the bones of the left hand were put in another piece of bag. Also, the bones of the right foot were put in a piece of bag, and the bones of the left foot in another piece of bag (Grygon et al., 2010). Other bones like the ribs, the vertebra, the scapular etc. in both bodies were separated after which the bones were put in the drum for boiling. Detergent $(10 \mathrm{~g}$ of OMO as an improvise in place of Biotex) was poured into the drum to aid the softening of the tissue. Water was poured into the container to feel the bones, the fire was kindled and the boiling process commenced (Grygon et al., 2010). The bones were boiled for a duration of 5 hours after which it was left till the next day so as to cool down.

\section{Second Round of De-fleshing}

Second round of de-fleshing refers to the removal of the remaining tissues still attached to the bones after boiling with the use of a knife and a scapel blade. The essence of this process is to have clean set of bones after boiling. That is, bones that are free of flesh or tissues. The bones were brought out of the water and the little flesh attached to it were removed. Due to the effect of the boiling, some of the tissues attached to the bones have already been removed.

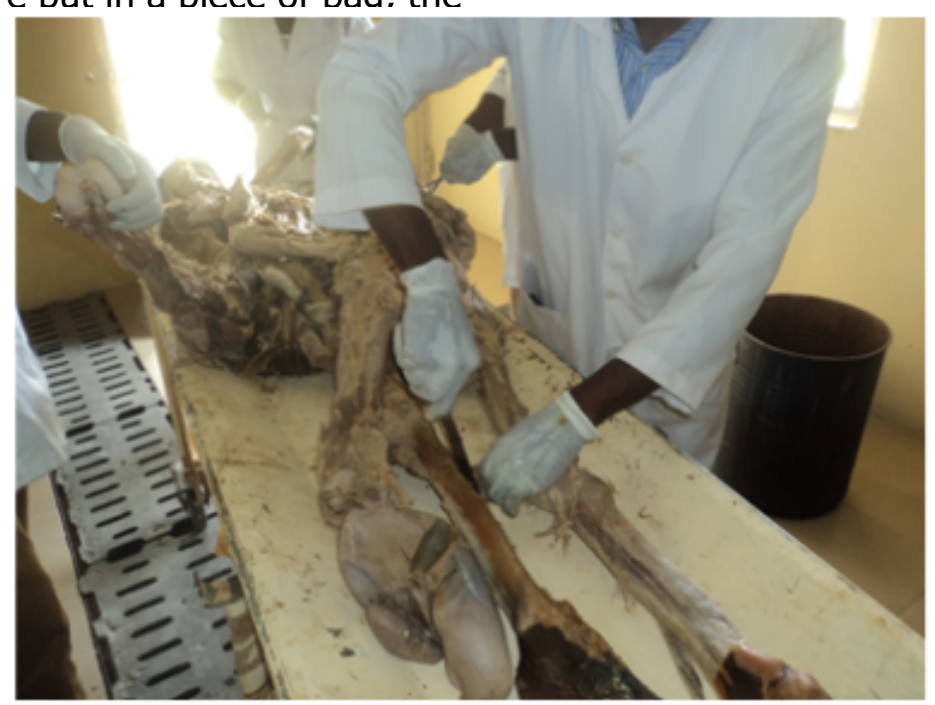

Figure 2: Showing the De-fleshing of the Male Cadaver using scalpel and knife to scrape the skin and muscles with their tendons from the bones. 

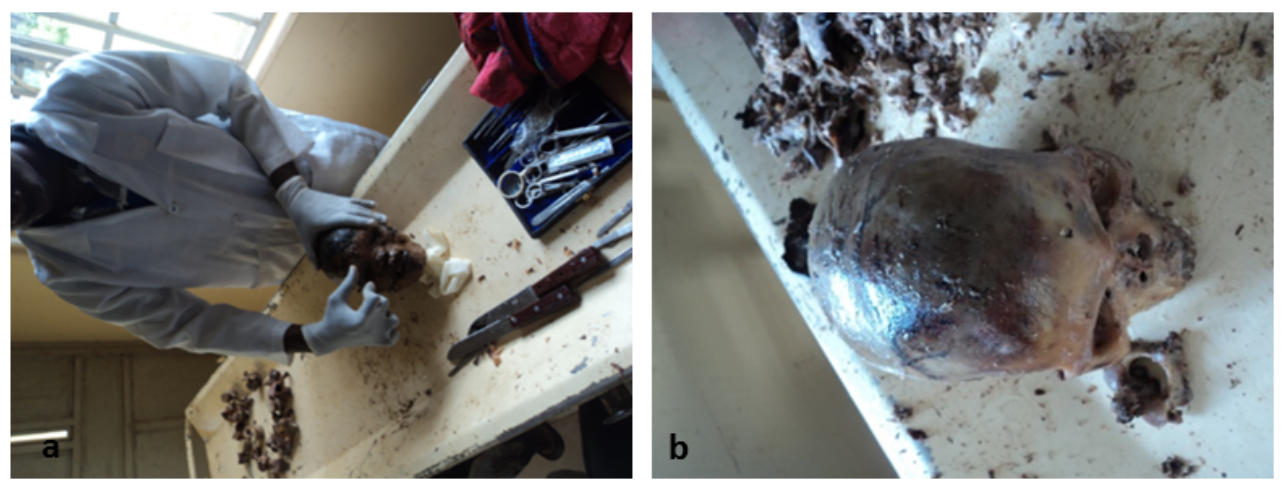

Figure 3: Showing De-fleshing after boiling during which all other strong tissues that could not be removed before boiling the bodies were easily removed after being softened by heat (hot water maceration).

\section{De-greasing}

Degreasing refers to the removal of grease from the bones. This is very important because greasy bones look dirty, attract more dust and don't bleach very well. There are several degreasing agents, all with their pros and contras. Examples include chloroform, benzene, acetone, trichloroethylene, ammonia (Grygon et al., 2010). It involves the immersion of the bones inside the degreasing agent which is aimed at removing all oily contents in the macerated bones, making the bones free of oil. The length of the degreasing period depends on how greasy the bones are; a minimum of 4 hours is recommendable (Grygon et al., 2010). This process was done in an open surrounding so as to avoid the inhalation of the poisonous chemical (von Endt et al., 1999). Chloroform was poured into a plastic container, and the bones were put inside (no dilution done) (Grygon et al., 2010). The bones were allowed to stay in the chloroform for 4 hours.

\section{Bleaching}

Bleaching refers to the whitening of bones. The chemical used was hydrogen peroxide (Fenton et al., 2003). One liter of hydrogen peroxide was mixed with 20 liters of water in a container of 22 liters, after which the bones were put inside the chemical. The bones were allowed to stay in the chemical for a period of 24 hours. We made sure that the bones of the male and female bodies were bleached separately. To avoid the bones becoming brittle, the bones were washed with soap and water immediately after removing them from the chemical.

\section{Washing}

After bleaching the bones, the bones were washed immediately with water and detergent this is very important so as to prevent white powder residue on the bones.

\section{Sorting out}

The bones were sorted out using an atlas and a skeleton model. The bones of the male body were sorted out from that of the female body. After drying of the bones, the bones were sorted out prior to the process of articulation.

\section{Drilling}

This is the process of drilling holes into the bones prior to the process of articulation. Holes were drilled into the bones using a drilling machine (Fig.4) and the size of the screw used is size number two.

A hole was drilled on the parietal bone of the skull, on both the sternal end and the acromial end of the clavicle, on the ulnar tuberosity and the dorsal (Lister's) tubercle of the ulnar, on the radial tuberosity of the radius, on the articular facets of the carpal bones, on the head and base of the metacarpal bones and on the head and base of the middle and proximal phalanges. The distal phalanges were articulated with an adhesive. For the lower limbs, holes were drilled on the head and the intercondylar fossa of the femur, on the inferior articular surface and on the oblique line of tibia, on the lateral malleolus 
of the fibula, on the articular facet of the sacrum, on the posterior superior iliac spine and the acetabulum of the pelvic bones, on the body of the calcaneus, on the articular surface of the cuboids and on the articular surface of the navicular with the cuneiform bones. Hole was also drilled on the articular surfaces of the cuneiforms, metatarsals, phalanges and on the trochlea of the talus. The Frank H. Netter's Atlas and an anatomy model were used as a guide.

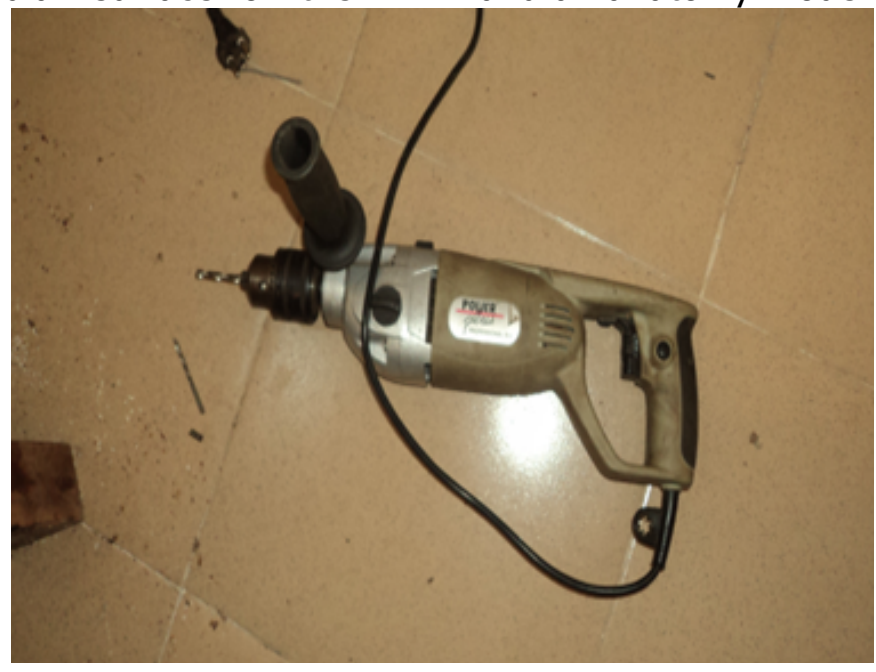

Figure 4: A Drilling Machine used to make holes into the bones for easy passage of wire for articulation.

\section{Articulation}

Articulation refers to the joining of bones. They were articulated in a way that the bones moved relatively to each other at a joint and they were constructed in a way that allow movement where necessary (Fenton et al., 2003).

The bones were articulated using wires and adhesive was used in some cases (Fig. 6a). A flexible iron rod was passed from the sacrum through the vertebral column to the skull and the atlas was articulated to the skull with an adhesive. The ribs 1-11 were attached to the vertebrae by articulating the head of each rib with the vertebral process of each vertebra bone. A modified sternum and costal cartilage was made, the modified coastal cartilage was attached to the ribs with wires and the modified costal cartilage was also attached to the modified sternum. The modified costal cartilage and sternum were painted yellow so as to distinguish it from the original bones. The vertebra bones were attached by adhering the body of the vertebra to a dunlop. The sacrum was attached to the iliac tuberosity of the pelvic bone using wires while the pelvic bones were attached at the symphyseal surface using dunlop as well. The head of the humerus was attached to the glenoid cavity of the scapula using wires and the clavicles were attached to the acromion of the scapula using wires. The neck of the radius was attached to the ulnar tuberosity using wire. The carpals, metacarpals and the phalanges of the upper limb were appropriately articulated using wires. The head of femur was attached to the acetabulum of the pelvic bone followed by the articulation of patellar to the patellar surface of the femur, superior articular surfaces of the tibia to the condyle of the femur, neck of the fibula to the tibia and all the tarsals, metatarsals and phalanges of the lower limb were also attached appropriately. Lastly, the mandible was attached to the skull.

\subsection{COLD WATER BONE MACERATION}

Cold water maceration is simply soaking the body in water until all the remaining flesh has been

removed. In this method, the skinned body was placed in an appropriate sized container covered with water and left to stand. However, more water was added when it was observed that the water level has reduced as a result of 
evaporation. The importance of cold water bone maceration is that it is easily done and will not damage or shrink the bones (Christenson, 2002). The protocol followed in the cold water bone maceration entails 10 rounds of de-fleshing (to hasten the process of soaking) with soaking in water following each round.

\section{De-greasing}

The process of degreasing was done in an open surrounding so as to avoid the inhalation of the poisonous chemical. It involved the immersion of the bones inside the degreasing agent which is aimed at removing all oily contents in the macerated bones, making the bones free of oil. Chloroform was poured into a plastic container, and the bones were put inside (no dilution done) left for 4 hours.

\section{Bleaching}

One liter of hydrogen peroxide was mixed with 20 liters of water in a container of 22 liters, after which the bones were put inside the chemical. The bones were allowed to stay in the chemical for a period of 24 hours. The bones were washed with soap and water immediately after removing them from the chemical to avoid them from becoming brittle.
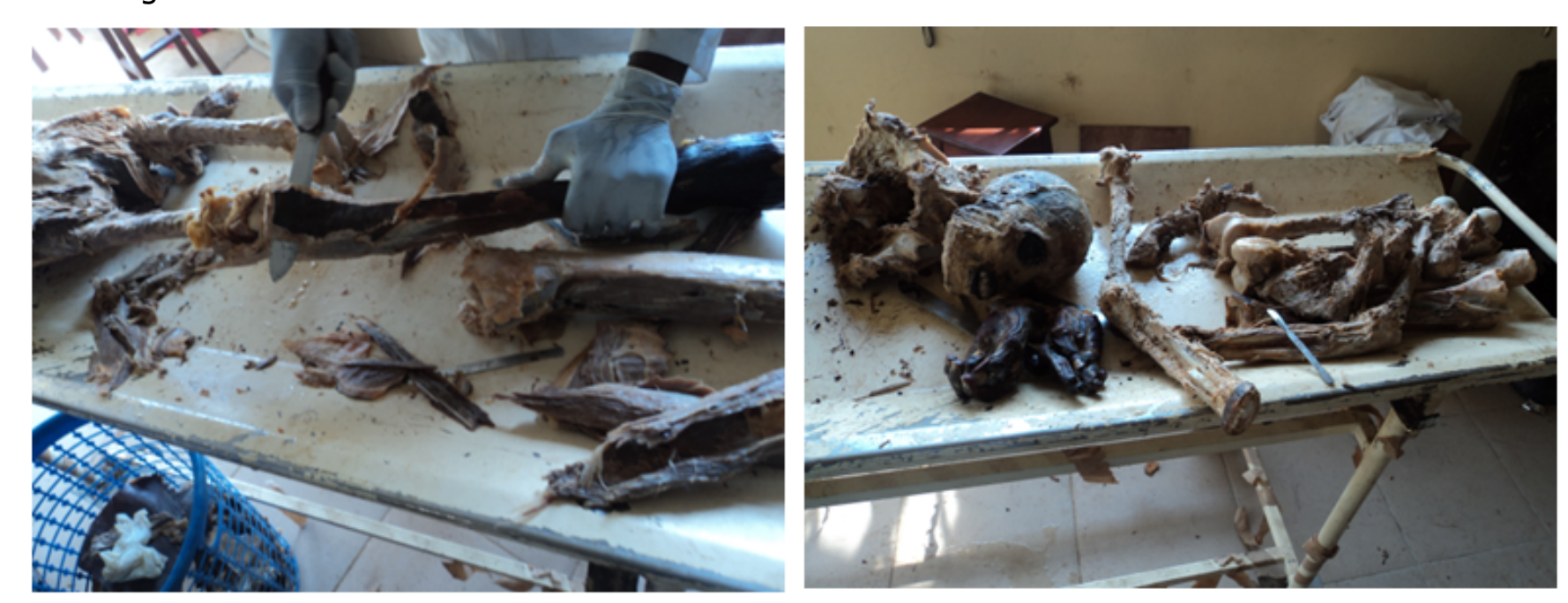

Figure 5a\&b: Showing Maceration during which the bones were disconnected from their various joints and more scrapins of tissues done.

\section{Washing}

After bleaching the bones, the bones were washed immediately with water and detergent. Although hydrogen peroxide was used for bleaching, it can have adverse effect on the bones if not washed away immediately as it can turn the bones brittle due to the continuous reaction of enzymes on the bones.

\section{Drying}

This involves the use of sunlight. The bones which are now wet were spread in the sun so as to dry up the water content.

\section{Sorting out}

The bones were sorted out using an atlas and a skeleton model. The bones of the male body were sorted out from that of the female body.

\section{Drilling}

This is the process of drilling holes into the bones prior to the process of articulation. The same procedure was followed as described in hot water maceration.

\section{Articulation}

Articulation of the bones was done as described above in hot water maceration method (Fig. 6b). 


\section{RESULTS}

Hot Water Bone Maceration

Hot water bone maceration is not the most ideal method of bone maceration. With this method, all the cartilages got dissolved. Most of the bones (especially the ribs, scapula and other small bones) got destroyed due to the deformation in the normal shape of the bones (shrinkage) which was caused by boiling. Also, the color of the bones changed after cooking the bones.

\section{Cold Water Bone Maceration}

Cold water maceration is the most preferred method of bone maceration. This method kept the bones white and maintained its integrity though it required a lot of time when compared to hot water bone maceration. Small bones had their flesh removed quickly on a scale of a few weeks, while larger and longer bones took months for the flesh to be removed. Cold water bone maceration is the best method of cleaning bones, it is the most "gentle" method to use if strong, solid and white bones are to be obtained as the end result. The following observations
However, this method is very much faster and less time consuming. The following observations were noted in the hot water bone maceration includes; change in color of the bones after boiling, shrinkage of the bones after boiling, oily substances were seen on the surface of the chloroform during the process of degreasing and the bones were very soft after bleaching but got harder after drying with sunlight.

were noted in cold water bone maceration; no change in color was observed after boiling the bones, no shrinkage of bones after boiling, oily substances were seen on the surface of the chloroform during the process of degreasing and the bones were very soft after bleaching but got harder after drying with sunlight. However, the results of this research study shows that long term storage of bones in formaldehyde favours cold water bone maceration procedures more than the hot water bone maceration procedures.

Table 1: Comparison of the Results Obtained from the two Methods

\begin{tabular}{|l|l|l|}
\hline PARAMETERS & $\begin{array}{l}\text { COLD WATER BONE } \\
\text { MACERATION }\end{array}$ & HOT WATER BONE MACERATION \\
\hline Duration & 2 months and 12 days & 3 weeks and 6 days \\
\hline Colour change & No change & Brownish red \\
\hline Smell & Very strong & Moderate \\
\hline Damaging effects & Very low & Higher \\
\hline $\begin{array}{l}\text { Bone recovery after maceration } \\
\text { procedures }\end{array}$ & High & Low \\
\hline
\end{tabular}

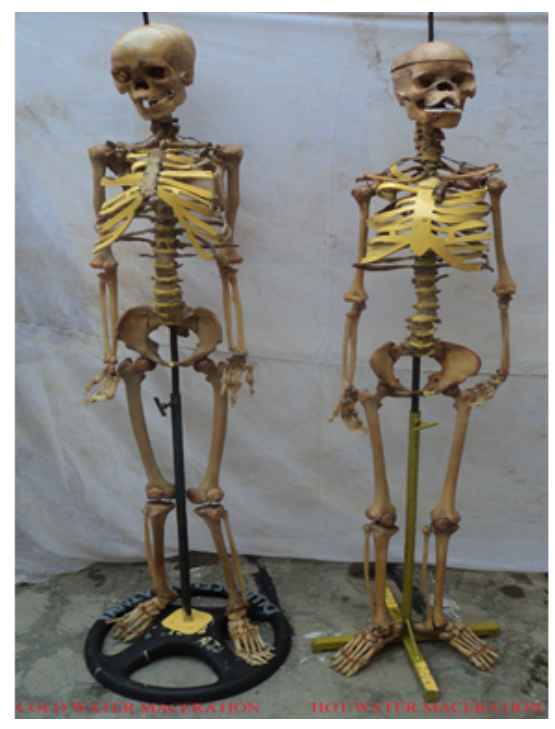

Figure 6: Complete Skeleton of the Hot Water and the Cold Water Bone Maceration showing the articulated skeleton and cartilages (improvised where necessary) into their various normal anatomical positions and the complete skeleton supported by standing metals. 


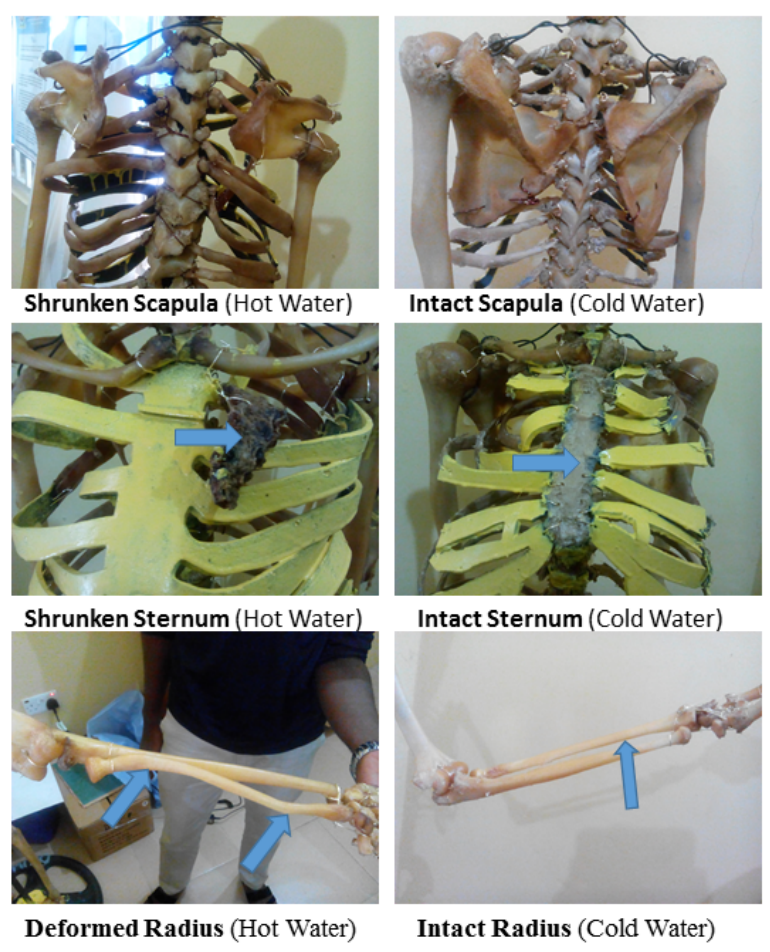

Figure 7: Bone Presentations after Hot and Cold-Water Maceration Procedures showing the appearance of the skeleton (thorax) anteriorly and posteriorly with the shrunken sternum and scapulae in the case of hot water maceration technique. The lonqs bone (radius) is also seen deformed (hot water maceration).

\section{DISCUSSIONS}

The present study observed that the smell of the bones was very strong in cold water maceration when compared to that of hot water. This method of maceration was also noted to be strenuous, time consuming and requires lots of patience and carefulness when removing the tissues from the bones. This is in tandem with the previous works done by Hussain et al. and Offele et al. in the year 2007. The bones had to be soaked for a period of two months and nineteen days before all the flesh on the bones could be removed.

Challenges encountered in cold water bone maceration are in varying degrees from the point of bone cleaning up to the point of articulation. However, the greatest challenge encountered in the cold water bone maceration was in the modification of the coastal cartilages of the ribs. Steadman et al., (2006) have reported that although hot water maceration is a very fast method, it is not the most suitable for bone maceration if bones of good integrity are to be obtained. The present study also agrees with this as the bones do not require soaking for tissue removal, instead they were boiled for a period of five hours, resulting into color changes in the bones. The color changed from its creamy white to a brownish red. Also, another notable change that was observed is the shrinkage of bones due to the effects of heat on the bones (Steadman et al., 2006). Four exceptional cases were noted during the period of boiling; the coastal cartilages were gone (they became dissolved by heat), the sternum became deformed by reducing in size when compared with other bones and it was observed that the water used in boiling became brownish in color with deposition of oily substances on its surface.

On the removal of the bones from bleaching solution in hot water maceration, the bones became softer than they were before bleaching. Though they were not as white as the bones of cold water maceration, they were also looking good and whitish. However, the bones became stronger after washing with soap and water and sun-drying. 
Challenges encountered in hot water bone maceration procedures were greater when compared to the challenges encountered in cold water bone maceration procedures. Among these challenges were the changes in the bones ranging from the color change and changes in the integrity of the bones during boiling water. The greatest challenge of all was the one encountered during the articulation of the bones. This is because most of the bones are now deformed and very smaller in size than they were before boiling. For this reason, various adjustments had to be made so that the bones will be well articulated and so that a neat articulation at least to some degree would be obtained.

Generally, though cold water bone maceration procedure in this research was very smelly and slow, the shrinkage of bones was avoided and a good integrity of bones were obtained similar to Christenson, (2002) reports. On the other hand, hot water bone maceration is less smelly and very fast compared to cold water bone maceration procedures. It caused the dissolution of bone tissues, changes in color of the bones and it is also a potential cause of damage and shrinkage of the bones. As a result, a good integrity of bones may not be obtained.

We conclude that cold water maceration when done properly results in much cleaner bones than the hot water method of cleaning though it takes a considerable amount of time to complete. Generally, this technique's major drawback is the irritating odor it produces, which if never experienced before may cause ill responses. Whereas, hot water bone maceration involves cooking the bones for hours until the soft tissues become soft enough to peel off. There are several problems with this method and the main one being that the bones becomes damaged due to heat making them soft and flaky. The results of the two methods of bone maceration employed in this research signify that the best method suitable for bone maceration is the use of cold water.

As furtherance to the findings in this study, further studies need to be carried out on the effects of different maceration techniques on Nuclear DNA Amplification of human bones. Also, further studies can be carried out on enzymes activities on the maceration of bones.

\section{REFERENCES}

1. Christensen AM. 2005. Testing the Reliability of Frontal Sinuses in Positive Identification. Journal of Forensic Sciences. 50: 1-5.

2. Fenton TW, Birkby WH. and Cornelison J. 2003. A Fast and Safe Non-Bleaching Method for Forensic Skeletal Preparation. Journal of Forensic Sciences. 48:274-276

3. Greene EA, Smith KR, Pendergraft JS, Raub RH, Arns MJ. 1993. Technical Note: Equine Skeletal Preservation Techniques to Enhance Teaching Effectiveness. J. Anim. Sci. 71:2270-2274.

4. Grygon D, Maxwell A. 2010. Tutorial cleaning of Bones PART 1. Available in: http://fav.me/d2lxlel

5. Hussain M, Hussain N, Hufsa Z, Saleem Q. 2007. Skeletal Preservation Techniques to Enhance Veterinary Anatomy Teaching. IJAVMS. 1: 21-23.

6. Offele D, Harbeck M, Dobberstein R, von Wurmb-Schwark N, Ritz-Timme S. 2007. Soft tissue removal by maceration and feeding of Dermestes sp.: impact on morphological and biomolecular analyses of dental tissues in forensic medicine, International Journal of Legal Medicine. 121: 341-348.

7. Steadman DL, Di Antonio L, Wilson J, Sheridan KE, Tammariello S. 2006. The effects of maceration on bone tissues. Journal of Legal Medicine, 128(2); 100-178.

8. Steadman DW, DiAntonio LL, Wilson JJ, Sheridan KE, Tammariello SP. 2006. The Effects of Chemical and Heat Maceration Techniques on the Recovery of Nuclear and Mitochondrial DNA from Bone. Journal of Forensic Sciences. 51:11-17.

9. van Gestel W. 2006. Cleaning Skulls and Skeletons by Maceration. Retrieved from http://www.wkulsit.com/misc/macerationmanual.htm.

10. von Endt DW, Ross CA, Hare PE. 1999. Initial results from cleaning small vertebrate skeletons using the enzyme trypsin. Collection Forum. 13: 51-62. 